\title{
Solar Radiation Changes in Japan during the 20th Century: Evidence from Sunshine Duration Measurements
}

\author{
Gerald STANHILL and Shabtai COHEN \\ Institute of Soil, Water and Environmental Sciences, ARO Volcani Center, Bet Dagan, Israel
}

(Manuscript received 6 September 2006, in final form 23 September 2007)

\begin{abstract}
Annual values of sunshine duration (SS) measured in Japan between 1890 and 2002 were used as a proxy for global irradiance $\left(\mathrm{E}_{\mathrm{g})}\right)$ to study trends and changes in solar forcing at the Earth's surface. Proxy relationships established for the two SS recorders used in the JMA network both yielded estimates of mean annual values of $E_{g \downarrow}$ with RMS $<6 \%$. A first order integrated moving average model (ARIMA) adequately described the time course of $\mathrm{SS}$ and $\mathrm{E}_{\mathrm{g} \downarrow}$, which indicated a small, irregular but significant annual increase in solar forcing during the $20^{\text {th }}$ century averaging $0.08 \mathrm{~W} \mathrm{~m}^{-2}$ or 2.3 hours of Jordan SS recorder sunshine, equivalent to $0.5 \%$ per decade. The rate of increase was four times the average in the first four and last three decades of the century reaching a maximum after 1980. The negative effect of the five major volcanic eruptions on $E_{g \downarrow}$ was shown to yield a significant linear negative forcing of $-41 \mathrm{~W} \mathrm{~m}^{-2}$ per unit AOD (stratospheric aerosol optical depth). The degree of negative solar forcing was related to latitude: between $25^{\circ}$ and $44^{\circ} \mathrm{N}$ each degree shift to the North was associated with an annual increase in $\mathrm{E}_{\mathrm{g} \downarrow}$ averaging $0.02 \%$. The time course of changes in solar radiation in Japan during the $20^{\text {th }}$ century resembled that measured in air temperature; correlations between annual values of $E_{g \downarrow}$ and those in the air temperature of the Northern Hemisphere were very highly significant $(\mathrm{P}<0.001)$ both for the concurrent and preceding year.
\end{abstract}

\section{Introduction}

Analyses of measurements of global solar irradiance at the Earth's surface $(\mathrm{Eg} \downarrow)$ made during the last 45 years show that widespread and significant changes have occurred. During the first 30 years $\mathrm{Eg} \downarrow$ decreased significantly by an average of $2 \%$ per decade with considerable spatial, largely latitudinal, variation (Stanhill and Cohen 2001). Around 1980 this large negative short wave radiative forcing at the Earth's surface, hereafter referred to as global dimming, came to an end and a recovery in $\mathrm{Eg} \downarrow$ started which has been termed global brightening (Wild et al. 2005). These changes are of major theoretical significance for climate change

Corresponding author: Gerald Stanhill, Institute of Soil, Water and Environmental Sciences, ARO Volcani Center, POB6, Bet Dagan 50250, Israel

E-mail: Gerald@agri.gov.il

(C2008, Meteorological Society of Japan studies in that the net reduction measured in $\mathrm{E}_{\mathrm{g} \downarrow}$ exceeds the increase estimated in the down-welling long wave radiation at the tropopause calculated to have resulted from man-made releases of 'greenhouse' gases (IPCC 2007). The magnitude of the changes in $\mathrm{Eg} \downarrow$ is also much larger than the positive short wave forcing at the top of the atmosphere caused by increased solar activity during the last century (Foukal 2002).

A major difficulty in establishing the causes of global dimming and brightening is the short duration and the limited number of accurate series of $\mathrm{Eg} \downarrow$ available for analysis. One way of extending the solar irradiance data base which has been used in this study, is to employ the longer and more numerous series of sunshine duration (SS) measurements available as a proxy measure.

Measurements of SS represent the time that direct solar beam irradiance exceeds $120 \mathrm{~W} \mathrm{~m}^{-2}$, the flux from the solar disc when it is more than $5^{\circ}$ 
above the horizon and unobscured by cloud (a parameter highly and negatively correlated with SS), mist, fog or haze (WMO 1997). Sunshine duration measurements began 150 years ago, and have been widely and successfully used for many years to estimate $\mathrm{Eg} \downarrow$ for periods of up to a month; the extensive literature on this proxy relation has been reviewed by Linacre (1992) and Martinez et al. (1984). More recently SS has been successfully used as a proxy on an annual time scale (Stanhill and Cohen 2005).

The three objectives of this study, based on the intensive monitoring of $E_{g \downarrow}$ and SS in Japan, were:

1) to establish the accuracy of annual values of $\mathrm{Eg} \downarrow$ estimated from corresponding annual values of SS measured with the Jordan photographic and the Eko rotating mirror sunshine recorders,

2) to examine temporal and spatial changes and trends in sunshine duration measured in Japan, and

3) to investigate possible causes of changes in $\mathrm{Eg} \downarrow$ during the last century.

\section{Measurements and methods}

The first measurements of sunshine duration in Japan made in 1890 with the Jordan photographic recorder (Middleton 1969) were reported in the Annual Report of the Central Meteorological Observatory of Japan. By 1900 routine measurements of SS made with the Jordan recorder were published for 15 stations; this number rose to 104 in 1910, to 138 in 1950, and then decreased to 121 in 1970. In 1986 the Jordan recorder was replaced as the station network recorder by the newly developed Eko rotating mirror instrument which eliminated the subjective element in the evaluation of SS (Akida, Aoshima and Miyake 1986). Katuyama (1987) found that the newer instrument gives lower values of SS, and reported that the average decrease in the measurements due to the change of instrumentation averaged 180 hours per year.

All the measurements used in our study were made and supplied by the Japanese Meteorological Agency (JMA) from their station network. This SS data base extended from 1890 to 2002 and the number of sites for which data was available for individual years within this period ranged from three to 67 . The number of stations analyzed was limited to the 65 stations with a minimum of 35 complete years of measurements with the Jordan recorder. The location of these stations is shown

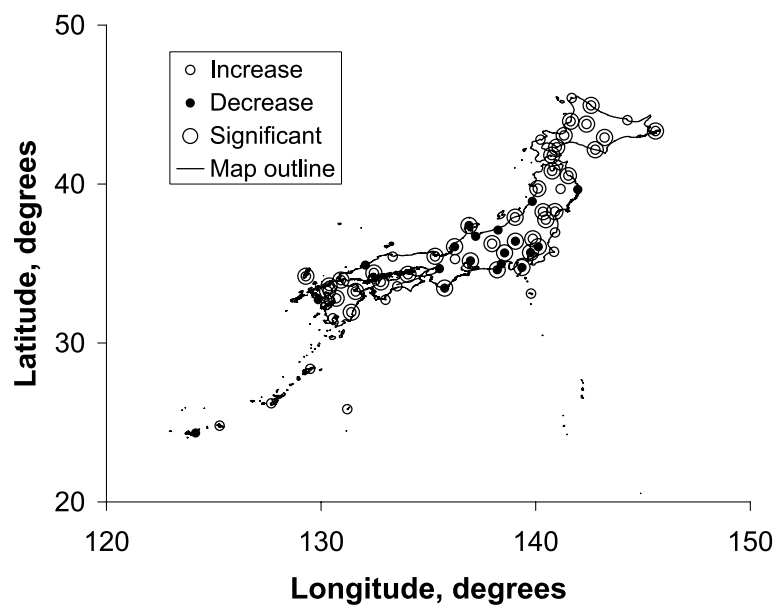

Fig. 1. Location of the 65 sunshine duration measurement sites in Japan providing the data analyzed in this study. A solid circle indicates measurement series with linear decreases in time, an open circle one with linear increases; time trends statistically significant at $\mathrm{P}<0.05$ are circled, those significant at $\mathrm{P}<0.01$ with two circles.

in Fig. 1, and the sign and statistical significance of the linear trends of SS at each measurement site is indicated. The mean latitude of the stations analyzed varied by less than $2^{0}$ during the period of the study. The data base consisted of 5480 station-years of which 4622 were measured with the Jordan and 758 with the Eko sunshine recorders.

Proxy relationships between $\mathrm{E}_{\mathrm{g} \downarrow}$ and SS were made using data from two models of calibrated thermopile pyranometers. $\mathrm{Eg} \downarrow \downarrow$ measured with the EKO MS-43(F) pyranometer was compared with contemporary SS measurements using the Jordan recorder, and $\mathrm{Eg} \downarrow$ measured with the Kipp en Zonen CM-21 pyranometer was compared with SS measurements made with the Eko recorder. Irradiances are expressed in units of $\mathrm{W} \mathrm{m}{ }^{-2}$, based on the World Radiometric Reference scale (WMO 1997).

Spectral (Fourier) analysis and autoregressive integrated moving average (ARIMA) model fitting were done with JMP version 5 software (SAS Institutes, Cary, N.C.). 


\section{Results}

\subsection{Annual sunshine duration as a proxy for an- nual global radiation}

Two proxy relationships were needed because of the substantial difference between daily values of SS measured with the Jordan and the Eko recorders shown by Katuyama (1987). The following comparison at six representative sites for eight years before and after the change of sunshine recorders shows that this was also true for the annual values of SS considered in our study.

At all six sites, which covered the two- fold range in the duration of annual sunshine duration occurring in Japan, SS was less when measured with the new instrument; on the average by 165 hours per year or $7.6 \%$. This reduction was not uniform: the maximum reduction of 328 hours per year or $21 \%$ was measured at Akita, a northern site with the lowest annual value of SS, 1536 hours. At Minamitorishima, the southernmost and sunniest site with an average sunshine duration of 2920 hours, the minimum reduction, 47 hours per year, or $1.6 \%$, was recorded.

A comparison of the 49 pairs of annual values of $\mathrm{Eg} \downarrow$ and SS measured with Eko pyranometers and Jordan recorders, respectively, and operating at 14 sites between 1983 and 1985 (Fig. 2), yielded a highly significant linear relationship with a root mean square error of $8.1 \mathrm{~W} \mathrm{~m}^{-2}, 5.4 \%$ of the mean annual value of $\mathrm{Eg} \downarrow$. Analysis of the pooled relationship shown in Fig. 2 indicates that variations in annual values of SS account for over one third $\left(\mathrm{r}^{2}\right.$ $=0.40$ ) of the total variation in annual sums of $\mathrm{Eg} \downarrow$.

$$
\mathrm{Eg} \downarrow=0.0348 \mathrm{SS}+77.9(\mathrm{r}=0.64, \mathrm{P}<0.001)
$$

The second comparison, based on 26 pairs of annual values measured with Kipp en Zonen pyranometers and Eko sunshine duration recorders operating at 12 sites between 1997 and 2002, also yielded a highly significant linear relationship with a root mean square error of $9.1 \mathrm{~W} \mathrm{~m}^{-2}, 5.8 \%$ of the mean annual value of $\mathrm{Eg} \downarrow$. The pooled relationship, shown in Fig. 2, indicates that variations in annual values of SS account for over half $\left(r^{2}=0.58\right)$ of the total variations in annual sums of $\mathrm{Eg} \downarrow$

$$
\mathrm{Eg} \downarrow=0.0444 \mathrm{SS}+74.7(\mathrm{r}=0.77, \mathrm{P}<0.001)
$$

The error introduced by using the above regional proxy relationships to estimate $\mathrm{Eg} \downarrow$ at an individual site was assessed using an independent data set. Estimates of $\mathrm{Eg} \downarrow$ based on SS measure-

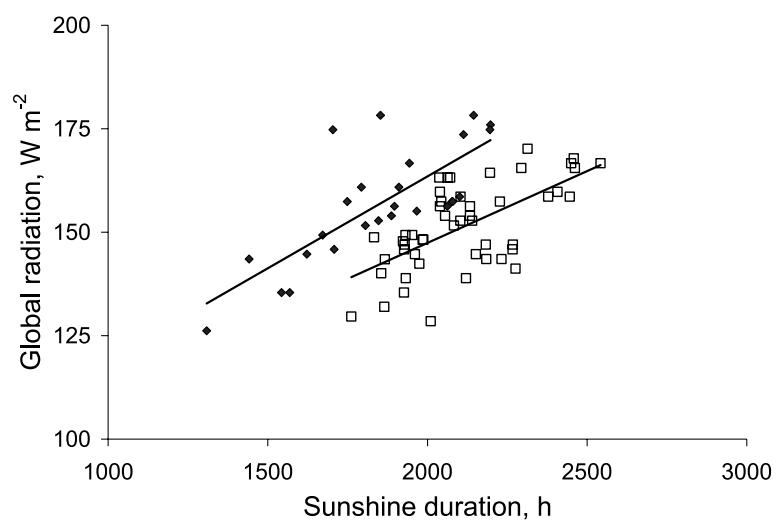

Fig. 2. Relationships between annual totals of global irradiance $\left(\mathrm{Eg} \downarrow, \mathrm{W} \mathrm{m} \mathrm{m}^{-2}\right)$ and sunshine duration (SS, hours) measured in Japan with the two JMA standard sunshine recorders and thermopiles. Solid diamonds indicate data from Rotating Mirrors and squares from Jordan recorders.

ments at Naha $\left(26^{\circ} 12^{\prime} \mathrm{N}, 127^{\circ} 41^{\prime} \mathrm{E}\right)$ with the regional proxy relationship, which did not include data from this site, were compared with on-site measurement of $\mathrm{Eg} \downarrow$. The 13 years of estimated and measured values at Naha were highly significantly correlated $(\mathrm{P}<0.01)$ with a mean difference of $7.42 \mathrm{~W} \mathrm{~m}^{-2}$ and a RSME of $34.9 \mathrm{~W} \mathrm{~m}^{-2}$.

\subsection{Autocorrelation in the time series, ARIMA mod- eling, and normality of the data:}

Using Eqs. (1) and (2), SS measurements from the 65 stations were converted to global radiation $(\mathrm{Eg} \downarrow)$, and the data were averaged annually to give a time series exceeding 100 years in length. Examination of the time series of yearly average values of Eg $\downarrow$ showed a high degree of autocorrelation that decreased monotonically with increasing lag (Fig. 3a). Since the confidence interval for random autocorrelations is approximately $2 / \sqrt{N}$, for the century long record the confidence interval is $\sim 0.2$, and the results indicate that the autocorrelations exceed those expected for a random distribution. For purposes of prediction and smoothing, this type of relationship is adequately dealt with by a first order autoregressive model, and in fact the autocorrelations of the residuals of such a model were all below the confidence interval. However, improvements in the statistics for a predictive model were obtained when first order 
a.

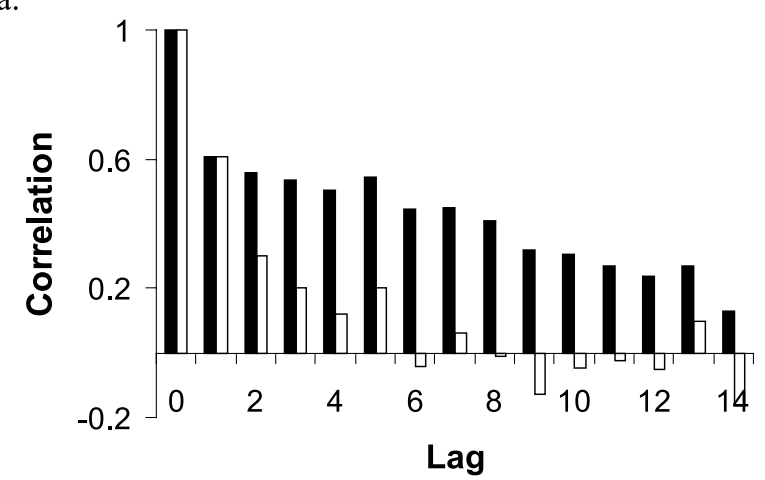

b.

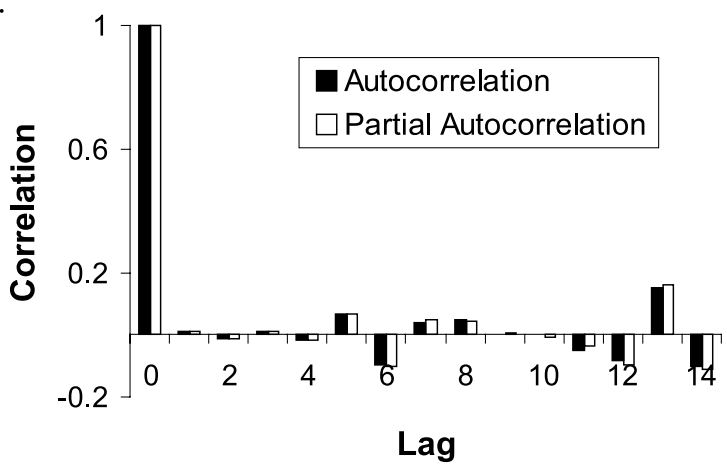

Fig. 3. Autocorrelations and partial autocorrelations for (a) the time series of global radiation and of (b) residuals from the $\operatorname{ARIMA}(1,1,1)$ model. integrated and moving average elements were introduced, such that a first order autoregressive, integrated moving average (ARIMA $(1,1,1))$ model gave a better fit. Autocorrelations for the residuals of the ARIMA(1,1,1) model are given in Fig. $3 \mathrm{~b}$, and it's parameters are given in Table 1 . As a check of the autocorrelative property of the time series, the 15 station data sets with more than 100 complete years of SS data were also examined (Table 1). In all cases autocorrelations for a two year lag (not shown) exceeded the confidence interval, and autocorrelations of residuals from first order ARIMA models did not. The moving average parameters for the ARIMA models (MA1), presented in Table 1, show a high degree of uniformity (coefficient of variation 25\%), with an average value of 0.77 , which we assume to be a characteristic of sunshine duration data from Japan.

Most of the individual time series were significantly linearly correlated with year of measurement (see below), and the slopes for this relationship are also given in Table 1 . In many cases, and especially when the magnitude of slope is large the amount of variance explained by the linear model is close to that explained by the ARIMA model.

Table 1. Coordinates, trends, and ARIMA $(1,1,1)$ parameters for the average of all SS series and for the 15 Japanese weather stations for which more than 100 full years of SS data are available.

\begin{tabular}{|c|c|c|c|c|c|c|c|c|c|c|c|c|c|}
\hline \multirow{2}{*}{ Station Name } & \multicolumn{2}{|c|}{ Latitude } & \multicolumn{2}{|c|}{ Longitude } & \multirow{2}{*}{$\frac{\text { Altitude }}{\mathrm{m}}$} & \multicolumn{3}{|c|}{ Dates } & \multirow{2}{*}{$\frac{\text { Linear }}{\text { slope }}$} & \multirow{2}{*}{$\begin{array}{c}\text { Linear } \\
\text { r square }\end{array}$} & \multirow{2}{*}{$\frac{\text { ARIMA }}{\text { r square }}$} & \multirow{2}{*}{$\begin{array}{c}\text { ARIMA } \\
\text { AR1 }\end{array}$} & \multirow{2}{*}{$\frac{\text { parameters }}{\text { MA1 }}$} \\
\hline & $\circ$ & ' & $\circ$ & ' & & start & end & \# years & & & & & \\
\hline Average of all & & & & & & 1890 & 2002 & 112 & 0.081 & 0.359 & 0.498 & 0.0164 & 0.753 \\
\hline Nemuro & 43 & 19.7 & 145 & 35.4 & 25.2 & 1890 & 2002 & 104 & 0.109 & 0.335 & 0.412 & 0.281 & 0.848 \\
\hline Hakodate & 41 & 48.8 & 140 & 45.4 & 35 & 1890 & 2002 & 109 & 0.08 & 0.186 & 0.159 & 0.197 & 0.835 \\
\hline Yamagata & 38 & 15.2 & 140 & 20.9 & 152.5 & 1895 & 2002 & 103 & 0.103 & 0.353 & 0.41 & 0.418 & 1 \\
\hline Niigata & 37 & 54.5 & 139 & 3 & 1.9 & 1892 & 2000 & 107 & 0.12 & 0.32 & 0.445 & 0.46 & 0.915 \\
\hline Maebashi & 36 & 24.1 & 139 & 3.8 & 112.1 & 1899 & 2002 & 101 & 0.01 & $0.002^{*}$ & 0.67 & -0.241 & 0.485 \\
\hline Tokyo & 35 & 41.2 & 139 & 45.8 & 6.1 & 1891 & 2002 & 110 & 0.006 & $0.001^{*}$ & 0.338 & -0.0065 & 0.68 \\
\hline Hikone & 35 & 16.4 & 136 & 14.8 & 87.3 & 1895 & 2002 & 101 & 0.049 & 0.09 & 0.206 & -0.154 & 0.601 \\
\hline Nagoya & 35 & 9.9 & 136 & 58.1 & 51.1 & 1891 & 2002 & 110 & 0.043 & 0.037 & 0.42 & -0.175 & 0.408 \\
\hline Hamada & 34 & 53.6 & 132 & 4.4 & 19 & 1899 & 2000 & 101 & 0.042 & 0.047 & 0.155 & 0.0963 & 0.816 \\
\hline Osaka & 34 & 40.7 & 135 & 31.3 & 23 & 1890 & 2001 & 109 & 0.043 & 0.052 & 0.27 & 0.309 & 0.847 \\
\hline Matsuyama & 33 & 50.4 & 132 & 46.8 & 32.2 & 1891 & 2002 & 104 & 0.088 & 0.175 & 0.388 & 0.223 & 0.48 \\
\hline Kochi & 33 & 33.9 & 133 & 33.1 & 0.5 & 1892 & 1998 & 102 & 0.117 & 0.222 & 0.504 & 0.458 & 0.982 \\
\hline Saga & 33 & 15.8 & 130 & 18.4 & 5.5 & 1893 & 2000 & 103 & 0.164 & 0.344 & 0.495 & 0.551 & 0.891 \\
\hline Kumamoto & 32 & 48.6 & 130 & 42.6 & 37.7 & 1891 & 2002 & 106 & 0.198 & 0.453 & 0.686 & 0.756 & 1 \\
\hline Nagasaki & 32 & 43.8 & 129 & 52.2 & 26.9 & 1897 & 2002 & 106 & 0.042 & 0.046 & 0.178 & 0.0793 & 0.804 \\
\hline mean & & & & & & & & & 0.081 & 0.178 & 0.382 & 0.22 & 0.77 \\
\hline stdev & & & & & & & & & 0.055 & 0.152 & 0.169 & 0.29 & 0.2 \\
\hline C.V. & & & & & & & & & 68 & 85 & 44 & 132 & 25 \\
\hline std error & & & & & & & & & 0.015 & 0.041 & 0.045 & 0.08 & 0.050 \\
\hline
\end{tabular}

${ }^{*}$ not significant 


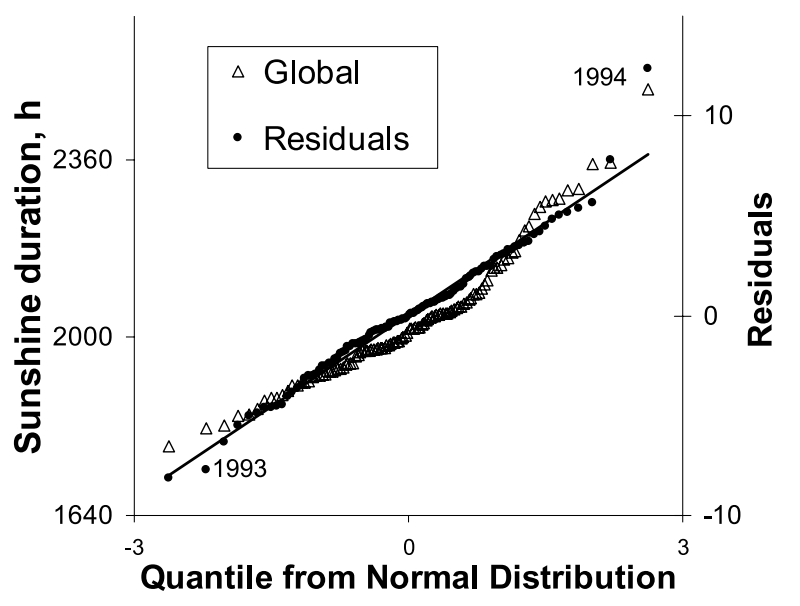

Fig. 4. Annual mean sunshine duration and residuals from the $\operatorname{ARIMA}(1,1,1)$ model sorted by size and plotted against the quantiles for a standard Normal distribution. The line is the linear fit to the residuals. Residual for 1993 and residual and sunshine duration for 1994 are indicated.

An additional feature of the time series is that the data, taken as a group, are not randomly distributed. This is seen when the mean annual sunshine duration values are sorted and plotted against the quantiles for a Normal distribution (Fig 4). When plotted this way, a Normally distributed population will fall on a straight line. In our case mid-range values are lower than expected, while the lowest and highest values are higher than expected. Figure 4 also shows a plot of the residuals from the ARIMA $(1,1,1)$ model plotted in the same way. The latter show greater conformity to the Normal distribution, as seen by their high degree of linearity, but a few of the highest and lowest points deviate significantly from the expected. These latter deviations indicate the to-be-expected inability of the predictive ARIMA model to deal with the large perturbations in the time series caused by years of volcanic eruptions (see below).

\subsection{Trends and changes in global radiation and sunshine duration in Japan}

The temporal course of annual sunshine duration for Japan between 1890 and 2004 is shown in Fig. 5 with the solid line representing the ARIMA $(1,1,1)$ fit. Equivalent values of global radiation are indicated on the secondary y-axis. Linear regression analysis of the individual yearly values

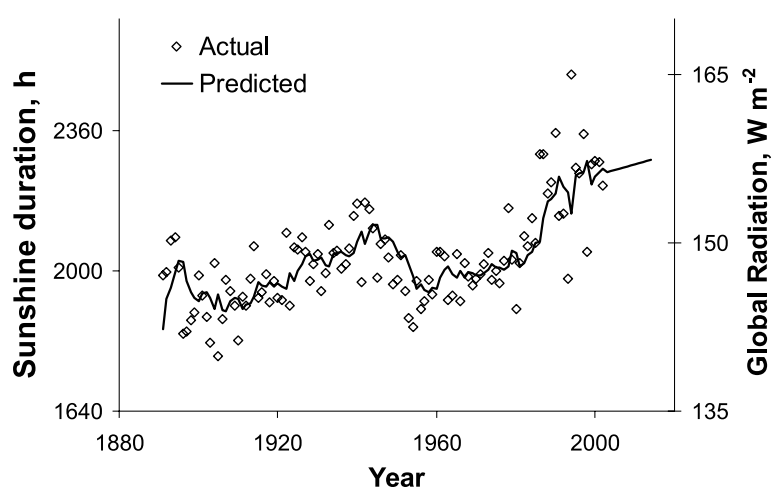

Fig. 5. Time trend of mean annual total sunshine duration and estimated $\mathrm{Eg} \downarrow$ (on the secondary y-axis) calculated from measurements between 1890 and 2002 with the appropriate proxy relationships. SS values are for the Jordan sunshine recorder. Data after 1986 measured with the Eko rotating mirror recorder were converted to $\mathrm{Eg} \downarrow$ and then to values for the Jordan recorder using the relationships in Fig. 2. The line represents the $\operatorname{ARIMA}(1,1,1)$ model fit.

indicates a small but statistically highly significant $(\mathrm{P}<0.01)$ mean annual increase equivalent to $0.080 \mathrm{~W} \mathrm{~m}^{-2}$ or 2.3 Jordan recorder SS hours, corresponding to $\approx 0.5 \%$ per decade. The smoothed curve in Fig. 5 shows some short term steeper changes, with values rising steeply from a minimum value at the beginning of last century to a secondary maximum 40 years later, followed by a fall to a secondary minimum in the mid-50's, later rising steeply from 1980 to reach maximum values at the end of the century.

Solar and atmospheric factors that could explain the changes seen in Fig. 5 were examined using the homogeneous SS data base measured with the Jordan recorder up to 1986 to eliminate errors introduced by the change in proxy relationships. For this analysis mean annual values of SS were expressed as the countrywide average of normalized anomalies for each site. Activity at the Sun's surface, represented by sun spot numbers (SSN) was not significantly correlated with mean annual values of SS anomalies. Four of the 65 series from individual sites were significantly $(\mathrm{P}<0.01)$ correlated with SSN, but these sites were not adjacent.

Transmissivity of the atmosphere was quantified as AOD values estimated by Sato et al. (1993) 
and Andronova et al. (1999) and obtained from the web site referred to in the latter publication. Values for the latitudinal zone between 30 and $45^{\circ}$ North latitude were assumed to be appropriate for Japan. Annual averages of AOD were weakly $(\mathrm{P}<0.10)$ correlated with mean SS anomalies; at eight of the 20 individual sites the correlations were significant at $\mathrm{P}<0.05$, at six sites the correlations were negative and at two positive.

The areal variation of time trends within Japan was examined on the basis of individual SS series measured with the Jordan recorder to ensure greater comparability between series by using the more homogeneous SS data base. Over half of the 65 SS series showed significant linear trends, 40 at $\mathrm{P}<0.05$ and 30 at $\mathrm{P}<0.01$. Thirty of the series with significant trends were positive, i.e. showed increases in the annual values of SS, and ten negative, indicating decreasing annual values. Averaging all the significant slopes yielded a mean increase of 1.71 hours per year, or $0.95 \%$ per decade. Areal variation in slopes was considerable, with standard deviations of 3.16 hours for absolute trend values and $0.161 \%$ for relative values. The slopes of the individual site trends was significantly $(\mathrm{P}<0.01)$ correlated with the latitude of the site; each degree shift northward being associated with a $0.188 \%$ per decade increase in SS or, in absolute terms, an increase of 0.333 hours SS per year $^{2}$ per degree. No statistically significant relationships were found between the size of the individual time trends and the longitude or altitude of the sites. Nor was there a significant association between the population size at the measurement site and the sign of the time trend or value of SS. However it may be noteworthy that the two sites showing the least increase in SS were Tokyo and Nagasaki, the two major urban centers (Table 1).

The effects of the five major eruptions occurring between 1900 and 2000 on SS can be distinguished even in the average values predicted by the ARIMA model (Fig. 5). A comparison of SS normalized anomalies during years of peak AOD, corresponding to volcanic eruptions, with years with low AOD values before and after the eruptions is shown in Table 2. Since the mean standard deviation of the proxy global radiation based on sunshine duration for all 65 stations is $6.24 \mathrm{~W}$ $\mathrm{m}^{-2}$, the mean decrease in the normalized anomaly ( $A n)$ during the 4 years, -0.43 , is equivalent to a decrease of $2.7 \mathrm{~W} \mathrm{~m}^{-2}$ in these years. Regressing the decrease in normalized anomaly on the AOD
Table 2. Average normalized anomalies of sunshine duration for years of peak yearly average AOD $(\mathrm{AOD}>0.04)$ following major volcanic eruptions between 1900 and 2000, when more than 30 stations measuring SS were in operation. Difference column is the difference between the value for that year and the average of the two background years.

\begin{tabular}{llrrrcc}
\hline \multicolumn{6}{c}{ Sunshine duration normalized anomaly } \\
\hline Year & AOD $\begin{array}{c}\text { That } \\
\text { year }\end{array}$ & Previous* & $\begin{array}{c}\text { Follow- } \begin{array}{c}\text { Average } \\
\text { ing* } \\
\text { back- } \\
\text { ground }\end{array} \\
\text { Difference }\end{array}$ \\
\hline 1903 & 0.074 & -1.15 & -0.45 & -1.06 & -0.75 & -0.4 \\
1912 & 0.098 & -0.66 & -0.47 & 0.17 & -0.15 & -0.51 \\
1969 & 0.041 & -0.33 & 0.02 & -0.14 & -0.06 & -0.27 \\
1983 & 0.075 & 0.22 & -0.04 & 0.84 & 0.4 & -0.18 \\
1992 & 0.119 & 0.65 & 1.69 & 1.15 & 1.42 & -0.77 \\
mean & 0.081 & -0.25 & 0.15 & 0.19 & 0.17 & -0.43 \\
\hline
\end{tabular}

${ }^{*}$ nearest year with AOD $<0.01$

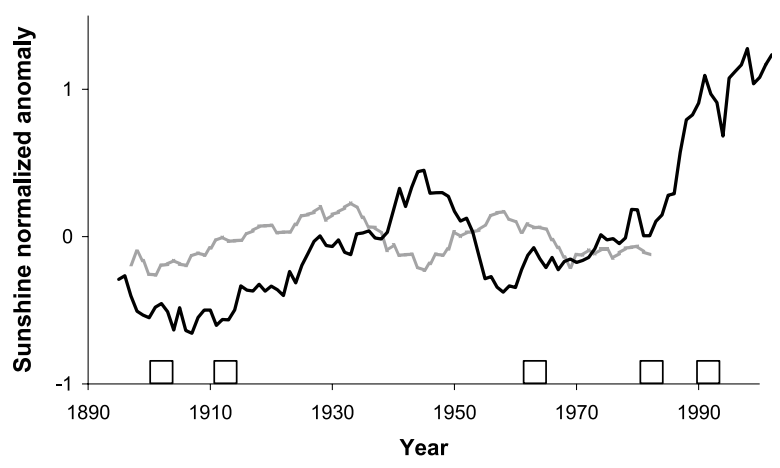

Fig. 6. Smoothed time series for normalized anomaly of annual sunshine duration in Japan (black) and the USA (gray) during the 20th century.

for this table (Fig. 7) gives a significant $(p<0.05)$ relationship:

$$
A n=-6.5^{*} \mathrm{AOD}+0.10\left(\mathrm{R}^{2}=0.69, \mathrm{p}<0.05\right)
$$

indicating a decrease of $4.1 \mathrm{~W} \mathrm{~m}^{-2}$ per 0.1 increase in AOD.

The presence of a significant periodic component in the distribution of the annual totals of SS, expressed as normalized anomalies, was tested by spectral analysis using the JMP Time Series program. The peak spectral density of the series of yearly values averaged for all sites for the years 1900-1985, occurred at a period of 4.3 years, with secondary peaks at 5.3 and 8.6 years. The periodic component of this series was significantly $(\mathrm{p}<0.05)$ 
greater than that to be expected from a population with a normal distribution (the white noise hypothesis) as shown by both the Fisher's Kappa (FK) and Bartlett's Kolmogorov-Smirnov statistic.

Values of peak and total spectral densities were also calculated for each of the 63 individual time series with 40 or more years of record. In 36 of the series the peak spectral densities were significantly $(\mathrm{p}<0.05)$ above white noise level as determined by the FK test. A higher proportion of sites with significant periodicities was found in the southern half of the country, ie. south of $33^{\circ} \mathrm{N}$, compared with those north of this latitude. The peak period of the significant spectral densities varied widely between individual sites: the median peak was at 9.6 years with a standard deviation of 6.7 years; one third of the series had significant peak spectral densities at a period of 4 years and only six i.e., one tenth of the series, had a peak at 22 years corresponding to the Schwabe sunspot cycle.

\section{Discussion}

\subsection{The accuracy of annual values of Eg $\downarrow$ estimat- ed from measurements of $S S$}

Limitations in the size of the data bases and lengths of the measurement series available for the two proxy relationships necessitated the pooling of spatial with temporal sources of variation. This limitation is common to many proxy relationships used to extend the length of time series available for analysis in climate change studies. Relevant recent examples are Kerr and Tabony (2004) and Stanhill and Cohen (2005). Despite these limitations the accuracy of the estimated annual values reported here, an RMS error term of $6 \%$ for the two proxy relationships, appears acceptable. It is similar to that obtained in the comparable USA study where the data base consisted of four years of measurements at 26 sites. The highly significant proxy relationship found in that study (Stanhill and Cohen 2005) had a slope of $0.0469 \pm 0.0021 \mathrm{~W} \mathrm{~m}^{-2} \mathrm{Eg} \downarrow$ per hour, similar to the slope of the post-1985 proxy reported here for Japan, 0.0444 (Eq. (2)). The error terms for annual estimates of regional $\mathrm{Eg} \downarrow$ based on SS measurements are two to three times greater than those of point measurements of $E_{g \downarrow}$ made directly with a well maintained and calibrated thermopile pyranometer (WMO 1997).

The validation test at Naha reported indicates that the error term for an individual site using the regional proxy was approximately four times greater than for estimates for an individual site made using an on-site proxy. This indication of significant spatial variation in the SS: $\mathrm{Eg} \downarrow$ relationship is supported by evidence from a world- wide data base which showed that latitude accounts for half of the spatial variation in the slopes of proxy relationships (Stanhill and Cohen 2005), a finding that can be explained by the fact that while the annual sum of SS is potentially independent of latitude, $\mathrm{Eg} \downarrow$ is strongly dependent on latitude.

The change in instruments used to measure SS (and in the proxy relationship) coincided with the marked increase in $\mathrm{Eg} \downarrow$ in the mid 1980's seen in Fig. 5. The possibility that this coincidence was an instrumental artifact can be rejected on the grounds that a world-wide global brightening phenomena occurred at this time, an increase which was also documented in a Japanese measurement series (Wild et al. 2005).

\subsection{Do trends in global radiation result from in- valid statistical analyses?}

There has been some concern that reported trends in global air temperatures and other climatic parameters may result from either invalid extrapolation of data (e.g., Soon et al. 2004) or from an "eyeball" selection from a random population of data points of a subset time series that happens to have linear time trends (Percival and Rothrock 2005). The latter study suggested that when selecting sub-sets in a time series the degrees of freedom are drastically reduced. In the current study we have demonstrated that the population of points for SS-proxy Eg $\downarrow$ is not random (Fig. 3) and it is therefore valid to expect that statistically significant sub-set time series exist. In addition, the positive time trend shown is significant for the full data set, and we have noted that there are smaller time trends in the data. Some of the latter are clearly related to volcanic eruptions as discussed in Section 4.3. These introduce nonNormal perturbations in the time series (Figs. 4, 5 and 7). The ARIMA(1.1.1) model used to give a smooth line for the data points was shown to be appropriate since it's residuals are Normally distributed, with the exception of the few points following the major volcanic eruptions in the $20^{\text {th }}$ century. The ARIMA model also adequately dealt with the high degree of autocorrelation in the century long SS series (Fig. 3) which indicates that the year to year variations in SS are not inde- 
pendent; if SS is high in one year, it is likely to be high in the following year(s). Thus, in Fig. 5, the ARIMA time series, originally developed as a tool for forecasting, is extended for a few years after the last data point and predicts that SS in Japan will remain high for the 8 coming years. Obviously, in the event of a volcanic eruption resulting in a high AOD, this prediction will not be true. The inability of the ARIMA model to predict such events is also demonstrated by the large deviation of the ARIMA residuals from the standard Normal curve for very large or small values of SS (Fig. 4).

\subsection{Trends and change in global radiation in Japan}

The major finding of this study, that global radiation in Japan increased significantly although irregularly during the last century, is in marked contrast to the evidence for a widespread reduction in $\mathrm{Eg} \downarrow$ on global, regional and individual site scales during the last half century (Stanhill and Cohen 2001). A bibliography of the published literature on global dimming, available at <http://www.rsbs. anu.edu.au/ResearchGroups/EBG/documents/ globaldimming_v2_000.pdf, includes an early account of global dimming from Japan (Sekihara 1973) reporting an $11 \%$ reduction in $\mathrm{Eg} \downarrow$ in Tokyo on cloudless days during the $1960-1970$ period as measured with an actinograph; this reduction was attributed to increases in industrial air pollution. The longer and more accurate 1972-2002 thermopile measurement series from Tokyo, which included the frequent cloudy days in the annual totals analyzed, showed no evidence for a continuation of this decline, rather its reversal.

A recently published analysis of long term records of $\mathrm{Eg} \downarrow$ measurements includes average values for Japan sites from the 1960's until 2002, based on a variety of pyranometer types (see supplementary material to Wild et al. 2005). That analysis shows a time trend approximated by a quadratic polynomial with a mid-1980 minimum. Our results, based on national average annual SS values for a century long period including theirs, show that global dimming, i.e., a decline in $\mathrm{Eg} \downarrow$ in Japan, was confined to a short post-war World War II decade between the mid 40's and the mid 50 's, and was followed 25 years later by a marked increase - i.e. global brightening.

Significant decadal increases in $\mathrm{Eg} \downarrow$ of a similar magnitude to those reported here for Japan after the 1960's, i.e., between 2 and 4\% per decade, were measured at four pyranometer stations in the North and North-Eastern coastal areas of Siberia. This region was the only area within the former Soviet Union (FSU) which showed global brightening during the 1964-1991 period (Abakumova et al. 1995). Other stations in the dense FSU network closer to, but westward of Japan, showed the global dimming phenomena common to this station network. Global dimming is also evident in an analysis of results from the Chinese national network (Che et al. 2005).

Approximately one thousand kms South-West of the Japanese mainland islands, significant reductions in $\mathrm{Eg} \downarrow$ were measured at Chichijima and Minamotoroshima, two remote island sites within the JMA network. Trends of -1.6 and $-5.7 \%$ per decade were recorded there between 1971 and 1991 (Stanhill and Moreshet 1994), however when analysis was extended to include data until 2001 these trends no longer significantly differed from zero.

Marked decreases in SS starting in the 1960s have been reported from two national station networks South and West of Japan; although problems of instrumental homogeneity exist in both data sets. The analysis from Taiwan was based on measurements from eight sites dating back to 1898 (Liu et al. 2002); that from mainland China on series measured at 65 sites starting in 1954 (Kaiser and Qian 2002). Both studies showed significant decreases.

Measurements in Eastern Asia show a regional variation in time trend similar to that within Japan noted in this study, i.e., that $\mathrm{E}_{\mathrm{g} \downarrow}$ and SS tend to increase with time to the North of the region and decrease to the South.

On a global scale the smoothed time trend of SS in Japan during the $20^{\text {th }}$ century is compared with that measured in the USA in Fig. 6 (for detail see Stanhill and Cohen 2005), where both trends have been expressed as smoothed curves of annual normalized anomalies. This shows that the temporal range of SS in Japan during the $20^{\text {th }}$ century was from +0.5 to -0.6 , twice that in the USA, +0.2 to -0.4 ; and maximums and minimums in Japan occurred approximately ten years after the USA. A major difference between the two time trends was that in Japan SS increased after 1960 while it decreased in the USA. In the USA the time course of SS was inversely related to the trends in precipitation and air temperature (Stanhill and Cohen 2005). In Japan there was no clear relationship between the trends in SS and precipitation but there 
was a positive correlation with air temperature (JMA 2003). This link with air temperatures extended to that of the mean surface air temperature of the Northern Hemisphere (NH) (Jones and Moburg 2003). The two series of annual values, i.e., SS duration and $\mathrm{NH}$ air temperature, were highly significantly correlated $\left(R^{2}=0.39, P<0.001\right)$, and to an even greater degree with the average air temperatures measured in the previous year $\left(\mathrm{R}^{2}\right.$ $=0.47, \mathrm{P}<0.001)$. These high correlations suggest that changes in $\mathrm{E}_{\mathrm{g} \downarrow}$ may play a more significant role in global warming than generally thought (IPCC 2001).

\subsection{Causes of changes in SS and Eg $\downarrow$}

Solar activity. Changes in solar activity during the $20^{\text {th }}$ century are estimated to have increased solar irradiance at the top of the atmosphere by 2 $\mathrm{W} \mathrm{m}{ }^{-2}$ (Foukal 2002); this increase is an order of magnitude less than that required to account for the change measured at the surface in Japan. The absence of a clear link with extra-terrestrial solar variations is confirmed by the results of the spectral analyses presented in Section 3.3.

Aerosols. The time course of atmospheric turbidity in Japan (i.e., an index of aerosol content), monitored since 1961 at a network of 14 stations, shows no evidence of a long term trend (JMA 2003). Therefore the long term increase in $E_{g \downarrow}$ in Japan cannot be explained as being due to a decrease in atmospheric aerosol load. Inter-annual variations in atmospheric turbidity were approximately 5\% except for years which followed major volcanic eruptions (Yamauchi 1995).

The effect of eruptions on SS was used to calculate their influence on $\mathrm{E}_{\mathrm{g} \downarrow}$ (see Section 3.3). On years following eruptions, (Table 2 and Fig. 7), mean $\mathrm{E}_{\mathrm{g} \downarrow}$ decreased by $2.7 \mathrm{Wm}^{-2}$. In 1984, the year after the El Chichon eruption, Eg $\downarrow$ in Japan averaged $4668 \mathrm{MJ} \mathrm{m}^{-2} \mathrm{yr}^{-1}$ as compared to the preceding and subsequent years, when $\mathrm{Eg} \downarrow$ was 4766 and $4774 \mathrm{MJ} \mathrm{m}^{-2} \mathrm{yr}^{-1}$, respectively. This is equivalent to a decrease of $102 \mathrm{MJ} \mathrm{m}^{-2}$ or $3.2 \mathrm{~W}$ $\mathrm{m}^{-2}$. However a comparison with the average of the two closest years in which AOD was less than 0.01, i.e. 1981 (4748 $\mathrm{MJ} \mathrm{m}^{-2}$ ) and 1988 (4471 MJ $\mathrm{m}^{-2}$, see Table 2) indicates that $\mathrm{Eg} \downarrow$ in Japan was not affected by the El Chichon eruption. Based on the decrease in SS measured at this time (Table 2) the reduction was equivalent to $1.1 \mathrm{~W} \mathrm{~m}^{-2}$.

The highest Feussner-Dubois turbidity coefficient of 4.6 was measured in Japan following the

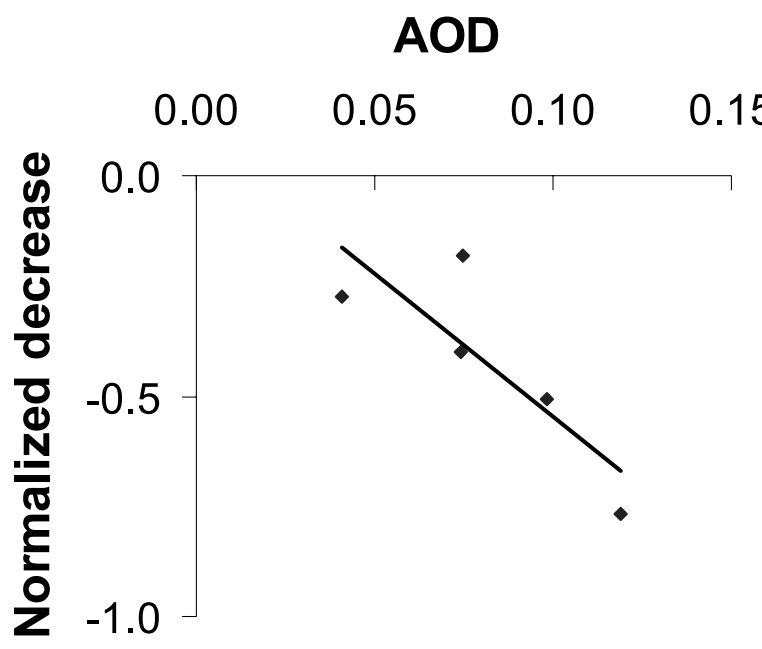

Fig. 7. Normalized decrease in solar radiation for years of peak AOD following major volcanic eruptions during the 20th century, plotted as a function of $\mathrm{AOD}$ (data in table 2). The line is from linear regression, where $\mathrm{Y}=-6.5 \mathrm{X}+0.10$, $\mathrm{r}^{2}=0.69(\mathrm{p}<0.05)$.

major Pinatubo eruption in 1991. This value was $131 \%$ of the network's long term average (JMA 2003). The average AOD rose to 0.032 and peaked at 0.119 in 1992 in the 30 to $45^{\circ} \mathrm{N}$ zone (Sato et al. 1993, Andronova et al. 1999). After four years turbidity and AOD levels returned to their preeruption levels. The normalized anomalies of SS measured in 1991 and 1992 were -1.01 and -0.77 respectively (Table 2), equivalent to decreases of 6.3 and $4.8 \mathrm{~W} \mathrm{~m}^{-2}$ in $\mathrm{Eg} \downarrow$. A comparable reduction of $6.1 \mathrm{~W} \mathrm{~m}^{-2}$, was obtained when global radiation in Japan during 1991 (4547 $\left.\mathrm{MJ} \mathrm{m}^{-2} \mathrm{yr}^{-1}\right)$ is compared with 4725 and 4753 , respectively the values for 1990, the year before the eruption, and 1995, the year when values of turbidity returned to their average.

Analysis of the major volcanic events during the $20^{\text {th }}$ century yields an estimate of the relationship between the peak stratospheric aerosol optical depth (AOD) and global irradiance, Eg $\downarrow$. The slope of the significant linear relationship shown in Fig. 7 indicates a decrease of $4.1 \mathrm{~W} \mathrm{~m}^{-2} \mathrm{Eg} \downarrow$ per 0.1 increase in AOD.

Clouds. The high correlation between cloud cover and sunshine duration on a diurnal and seasonal basis is well established. However it was not possible to test the hypothesis that the annual 
changes in SS documented here were caused by changes in cloud cover or properties as this data was not available, neither for individual stations nor as national averages. The analysis of world wide aggregated surface observations of cloud cover during the 1971-1996 period shows that cloud cover over Northern Japan increased by $1 \%$ per decade and by $0.2 \%$ per decade over Southern Japan (Warren et al. 2004). This increase coincided with the increased SS shown in Fig. 5. This result is opposite to the inverse linear relationship between cloudiness and SS established for diurnal and seasonal relationships.

\section{Conclusions}

Five thousand four hundred and eighty stationyears of sunshine duration measurements from 65 widely distributed stations over the 1890 to 2002 period were selected from the Japan Meteorological Agency's data base and used to estimate annual, regional mean values of global radiation in Japan. The two proxy relationships developed for this purpose were shown to be robust and yielded regional estimates of $\mathrm{Eg} \downarrow$ with accuracies of $6 \%$.

During the $20^{\text {th }}$ century SS in Japan increased by $10 \%$. Half of this increase occurred between 1900 and 1940 and was followed by a small and irregular decrease till 1950 . Subsequently the increase of SS in Japan accelerated, especially since the mid 1980's. This temporal pattern resembles the changes in the average air temperature both for Japan and more so for the Northern Hemisphere. The unknown mechanism coupling these two parameters merits further study.

The decadal trends in Japan, expressed as normalized anomalies for the purpose of comparison, showed some similarity with those previously shown in the USA; the range was greater in Japan and there was a ten year lag in peaks and troughs. Another contrast was the absence of the marked decrease in $\mathrm{Eg} \downarrow$ (global dimming) after 1960 found in the USA (Liepert 2002) and much of the Northern Hemisphere. This absence of the widely reported global dimming phenomenon has a regional aspect. It was especially evident in northern Japan and extended northwards to NorthEastern Siberia. The causes of the increase in sunshine duration and global radiation could not be established unequivocally since the most likely cause is changes in cloud cover, but cloud data were not available. The long series of atmospheric turbidity measurements available showed no long term changes that could explain the increase in $\mathrm{Eg} \downarrow$. Nor were the magnitude and timing of the estimated increases in solar activity during the $20^{\text {th }}$ century compatible with the changes at the surface measured in Japan.

The effects of two major volcanic eruptions, El Chichon and Pinatubo, on SS and Eg $\downarrow$ were shown to be substantial but short lasting. Analysis of the years of peak stratospheric aerosol optical density AOD following the five major eruptions that occurred in the $20^{\text {th }}$ century, gave a significant inverse relationship with a slope of $-41 \mathrm{~W} \mathrm{~m}^{-2}$ $\mathrm{AOD}^{-1}$.

\section{Acknowledgments}

We wish to thank the Japan Meteorological Agency who supplied the sunshine duration data base analyzed in this study, and in particular Masamichi Nakamura, head of the Radiation Section of Atmospheric Environment Division of the JMA for information concerning the measurements which he supplied, and the anonymous reviewers for their constructive comments.

\section{References}

Abakumova, G.M., E.M. Feigelson, V. Bussak, and V.V. Stadnik, 1996: Evaluation of long term changes in radiation, cloudiness and surface temperature on the territory of the former Soviet Union. $J$. Climate, 9, 1319-1327.

Andronova, N.G., E.V. Rozanov, F. Yang, M.E. Sclesinger, and G.L. Stenchikov, 1999: Radiative forcing by volcanic aerosols from 1850 to 1994. J. Geophys. Res.-Atm., 104 9d14, 1807-16826.

Che, H.Z., G.Y. Shi, X.Y. Zhang, R. Arimoto, J.Q. Zhao, L. Xu, B. Wang, and Z.H. Chen, 2005: Analysis of 40 years of solar radiation data from China, 1961-2000. Geophy. Res. Lett., 32, L06803, doi: 10.1029/2004GL022322.

Foukal, P., 2002: A comparison of variable solar and ultraviolet irradiancies in the 20th century. Geophys. Res. Lett., 29, 23, doi: 10.1029/2002GLO 15474.

Ikeda, H., T. Aoshima, and Y. Miyake, 1986: Development of a new sunshine duration meter. $J$. Meteor. Soc. Japan, 64, 987-993.

IPCC, 2001: Climate Change 2001. The Scientific Basis. Contribution of Working Group 1 to the Third Assessment Report of the Intergovernmental Panel on Climate Change. Cambridge University Press, Cambridge, 881 pp.

Jones, P.D. and A. Moburg, 2003: Hemispheric and large-scale surface air temperature variations: An extensive revision and update to 2001. J. 
Climate, 16, 206-223.

JMA, 2003: Annual Report on Atmospheric and Marine Environment Monitoring No. 3 Observational Results for 2001. CD disc. Japanese Meteorological Agency, 2003. Atmospheric Turbid.

Kaiser, D.P. and Y. Qian, 2002: Decreasing trends in sunshine duration over China for 1954-1998: Indication of increased haze pollution? Geophys. Res. Lett., 29(21), 2042, doi: 10.1029/2002GLO16057.

Katuyama, K., 1987: On comparison between rotating mirror sunshine recorder and Jordan sunshine recorder. Weather Service Bureau, 54, 169-83 (in Japanese).

Kerr, A. and R. Tabony, 2004: Comparisons of sunshine recorded by Campbell-Stokes and automatic sensors. Weather, 59, 90-95.

Liepert, B.G., 2002: Observed reductions of surface solar radiation at sites in the United States and world wide from 1961 to 1990 . Geophys. Res. Lett., 29/12, 10-1029/2002GLO149.

Linacre, E., 1992: Climate data and resources. Routledge, London, 180-181.

Liu, S.C., C.-H. Wang, C.-J. Shiu, H.-W. Chang, C.-K. Hsaiao, and S.-H. Liaw, 2002: Reductions in sunshine duration over Taiwan: causes and implications. Tao, 13, 523-545.

Martinez, J.A., F. Tena, J.E. Onrubia, and J. De la Rubia, 1984: The historical evolution of the Angstrom formula and its modifications. Agric. For. Meteorol., 33, 108-128.

Middleton, W.E. Knowles., 1969: Invention of the Meteorological Instruments. The John Hopkins Press, Baltimore, 231-244.

Percival, D.B. and D.A. Rothrock, 2005: "Eyeballing" trends in climate time series: a cautionary note. $J$. Climate, 18(6), 886-891.

Rebetz, M. and M. Benison, 1998: Changes in sunshine duration are correlated with changes in daily temperature range this century; An analysis of Swiss climatology data. Geophys. Res. Lett., 25, 3611-3613.

Sato, M., J.E. Hansen, M.P. McCormick, and J.B. Pollack, 1993: Stratospheric aerosol optical depths, 1850-1990. J. Geophys. Res.Atm, 98(D12), 22987-
22994.

Sekihara, K., 1973: Some aspect of radiation climate of Tokyo as observed by the eleven year measurement of spectral global radiation from 1961 to 1971. J. Meteor. Soc. Japan, 51, 119-132.

Soon, W.W.-H., D.R. Legates, and S.L. Baliunas, 2004: Estimation and representation of long-term $(>40$ year)trends of Northern-Hemisphere-grided surface temperature: A note of caution. Geophys. Res. Lett., 51, L03209: doi: 10.1029/2003GLO 19141.

Stanhill, G. and S. Moreshet, 1994: Global radiation change at seven sites remote from surface sources of pollution. Climatic Change, 26, 89103.

Stanhill, G. and S. Cohen, 2001: Global dimming: a review of the evidence for a widespread and significant reduction in global radiation with discussion of its probable causes and possible agricultural consequences. Agric. For. Meteorol., 107, 255-278.

Stanhill, G. and S. Cohen, 2005. Solar radiation changes in the United States during the 20th century: Evidence from sunshine duration measurements. J. Climate, 18, 1503-1512.

Warren, S.G., Eastman, R., and C. Hahn, 2004: Recent changes in cloud cover and cloud types over land. Abstract for GEWEX meeting. 3-5 November 2004, Paris. 67.

Wild, M., H. Gilgen, A. Roesch, A. Ohmura, C.N. Long, E.G. Dutton, B. Forgan, A. Kallis, V. Russak., and A. Tsvetkov, 2005: from dimming to brightening: decadal changes in solar radiation at the Earth's surface. Science, 308, 6 May 2005, 847850.

WMO, 1997: Measurement of Radiation. Guide to Meteorological Instruments and Methods of Observations, 6th Edition. World Meteorological Organization, Geneva (Chapter 7).

Yamauchi, T., 1995: Statistical analysis of atmospheric turbidity over Japan: The influence of three volcanic eruptions. J. Meteor. Soc. Japan, 73, 91103. 